\title{
GROWTH OF InAsSb/InAs MQW AND InPSb BY GAS SOURCE MOLECULAR BEAM EPITAXY
}

\author{
Gene Tsai and Hao-Hsiung Lin \\ Graduate Institute of Electronics Engineering and Department of Electrical Engineering \\ National Taiwan University \\ R419, Dept. of EE, NTU, No. 1 Sec, 4 Roosevelt Rd., Taipei, Taiwan, 106 \\ Phone: +886223635251, ext 419 Fax:+886223632442, E-mail: hhlin@ntu.edu.tw
}

Abstract-We report the growth of InAsSb/InAs MQWs and InPSb by MBE. The incorporation behaviors of Sb as well as the optical properties are discussed. InPSb with only 65 arcsec DXRD linewidths is obtained.

\section{INTRODUCTION}

Mid-infrared (mid-IR) $(\lambda=3 \sim 5 \mu \mathrm{m})$ light sources and detectors have attracted more and more attention recently because of their widely applications in monitoring and sensing of trace gases such as $\mathrm{CH}_{4}, \mathrm{NO}_{2}, \mathrm{H}_{2} \mathrm{~S}, \mathrm{SO}_{2}$ and $\mathrm{CO}_{2}$ with the fundamental absorption bands in this range (1-3). Antimonide-based heterostructure InAsSb/InAs(PSb) is one of the important materials for this wavelength range. The InAsPSb of the aluminum-free heterostructure can be grown with the lattice matched to InAs substrates and serves as either cladding layer or barrier layer for the heterojunction devices (4-6). InAs(PSb) based W-shape quantum well laser diodes have been successfully demonstrated (4). However, almost all the InAs(PSb) materials reported in literatures were grown by MOCVD. In this study, we report the InAs\$b/InAs strained multiple quantum wells (MQWs) and bulk InPSb laycrs grown by GSMBE.

\section{EXPERIMENT}

Gas-source VG-V80H MBE system was used to grow the InAsSb/InAs MQWs and InPSb bulk layers of this study. Basically, these samples were deposited on InAs substrates. For Hall measurement, some InPSb layers were also deposited on semi-insulating GaAs substrates. For InAsSb/InAs MQWs, we used a Riber As valved cracking cell to provide $\mathrm{As}_{2}$ beam. The cracking zone temperature of the cell was $900^{\circ} \mathrm{C}$. The $\mathrm{Sb}$ beam was from an EPI Sb cracking cell. The cracking zone of the $\mathrm{Sb}$ cell was set at $1000^{\circ} \mathrm{C}$, and the cracked species in the beam include $\mathrm{Sb}$ monomer and $\mathrm{Sb}_{2}$ dimer (7). A general thermal effusion K-cell was used to provide group-III In flux. To begin with the growth, an InAs buffer layer was firstly deposited on the substrate at $470 \sim 480^{\circ} \mathrm{C}$. Seven-period InAsSb/InAs MQW was then grown on the buffer layer at $450^{\circ} \mathrm{C}$. The thickness of the
InAs barrier and the InAsSb well are $15 \mathrm{~nm}$ and $5 \mathrm{~nm}$, respectively. Two growth rates $(0.5 \mu \mathrm{m} / \mathrm{hr}$ and $1 \mu \mathrm{m} / \mathrm{hr})$ were employed to investigate their effect on the Sb composition. For the growth of InPSb bulk layers, besides the Sb source, we used $\mathrm{P}_{2}$ beam cracked from phosphine $\left(\mathrm{PH}_{3}\right)$ gas as the $\mathrm{P}$ source. The cracking zone of the gas $\mathrm{K}$-cell was set at $1000^{\circ} \mathrm{C}$. The substrate temperature of the InPSb bulk layer was chosen to be the same as that of InAsSb/InAs MQWs $\left(450^{\circ} \mathrm{C}\right.$ ), and the growth rate was set at $1 \mu \mathrm{m} / \mathrm{hr}$. During the growth, in-situ reflection high energy electron diffraction (RHEED) paltern was used to monitor the surface reconstruction, After the growth, double crystal X-ray diffraction (DXRD), photoluminescence (PL) and Hall measurement were employed to inspect the structural and optical properties of the samples.

\section{UI. RESULT AND DISCUSSION}

Before growing a scries of InAs\$b samples, three InAsSb/InAs five-period MQW samples, C1466, C1464, and C1467, were grown at three different substrate temperatures, namely, $420^{\circ} \mathrm{C}, 450^{\circ} \mathrm{C}$, and $480^{\circ} \mathrm{C}$, in respectively. During the growth of the MQWs, the in-situ RHEED pattern showed clear $4 \times 2$ reconstructions when InAs was deposited, and became slightly blurry when InAsSb was deposited. It implies a rougher growing surface when $\mathrm{Sb}$ was incorporated. However, the satellite peaks in the XRD spectrums of these samples show only $\sim 80$ arcsec linewidths, indicating good crystal quality. After the growth, PL was performed to examine their optical quality. Fig. 1(a) shows the low temperature (10K) PL spectrums of the three samples. As can be seen, under the same excitation level, C1464 has the strongest peak intensity among the three samples. The emission peaks for $\mathrm{C} 1466, \mathrm{Cl} 464$, and $\mathrm{Cl} 467$ are located at $3.32 \mu \mathrm{m}, 3.25 \mu \mathrm{m}$, and $3.23 \mu \mathrm{m}$, respectively. The minor descending peak wavelength in these three samples is due to 


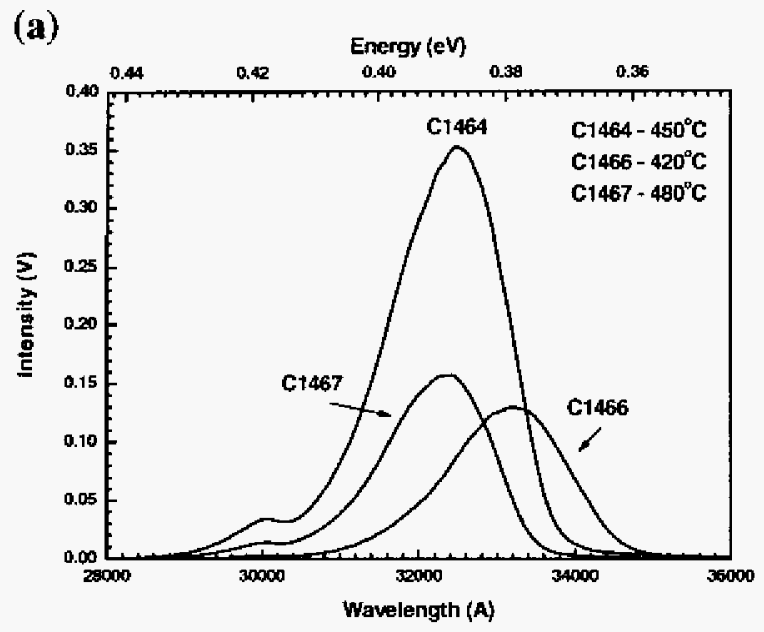

(b)

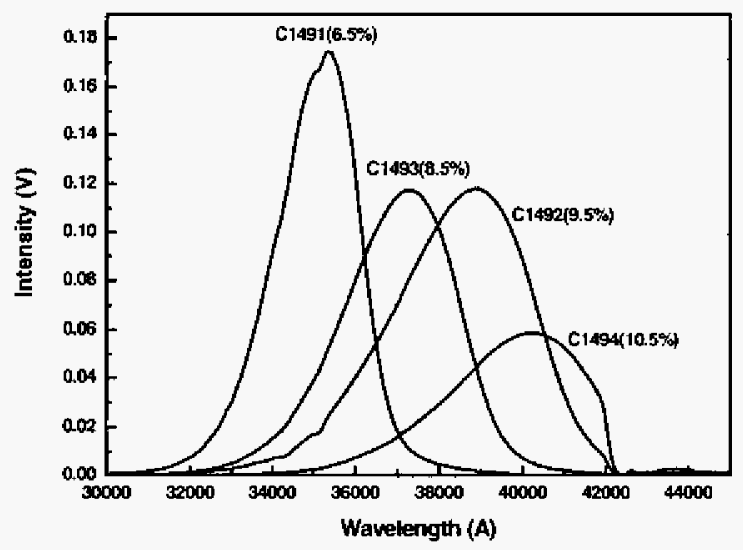

Fig. 1 (a) Photoluminescence spectrums of InAsSb/InAs MQW samples with different growth temperature. Among them, Cl464 (grown under $450^{\circ} \mathrm{C}$ ) has the strongest peak intensity. The emission wavelength is $3.25 \mu \mathrm{m}$. (b) Wavelength of PL pcak shift to longer wavelength as $\mathrm{Sb}$ composition increases in alloy.

their different growth temperatures, which implies that higher growth temperature slightly decreases the $\mathrm{Sb}$ incorporation in InAsSb. The Sb compositions determined by DXRD in these samples are around 0.037. Based on the PL result, the substrate temperature of $450^{\circ} \mathrm{C}$ was selected for the rest growths. Fig. 1(b) shows the PL spectrums of the InAsSb/InAs $\mathrm{MQW}$ samples with different $\mathrm{Sb}$ composition (from 0.065 to 0.105 ). Obviously, the increment in $\mathrm{Sb}$ composition reduces the InAsSb bandgap and leads longer PL emission wavelength. All the samples show strong PL intensity. The rapid decrement in the right shoulder of sample C1494 is due to the absorption of $\mathrm{CO}_{2}$.
The solid $\mathrm{Sb} / \mathrm{As}$ mole ratio in InAsSb versus $\mathrm{Sb} / \mathrm{As}_{2} \mathrm{BEP}$ ratio plot is shown in Fig. 2. Two series of InAsSb/InAs QW samples with different growth rate are depicted in the figure. The solid composition is determined from DXRD analysis. Basically, InAsSb contains two volatile group-V elements. The solid composition control is more complicated than that for alloy with only one volatile group- $V$ element. In literatures, theoretical models including kinetic model $(8)$ and thermodynamic model $(9,10)$ have been proposed to explain the incorporation behavior of alloy with two group- $V$ elements. For samples with $0.5 \mu \mathrm{m} / \mathrm{hr}$ growth rate, it is clearly that the solid $\mathrm{Sb} / \mathrm{As}$ mole ratio is not linearly dependent on the $\mathrm{Sb} / \mathrm{As}_{2}$ BEP ratio, which indicates that the sticking coefficient of $S b$ is not a constant (11). As we can see in the figure, the curve for the samples with $0.5 \mu \mathrm{m} / \mathrm{hr}$ growth rate has larger slope in the low BEP ratio region than in the high BEP ratio region. This incorporation behavior can be fitted quite well by using the

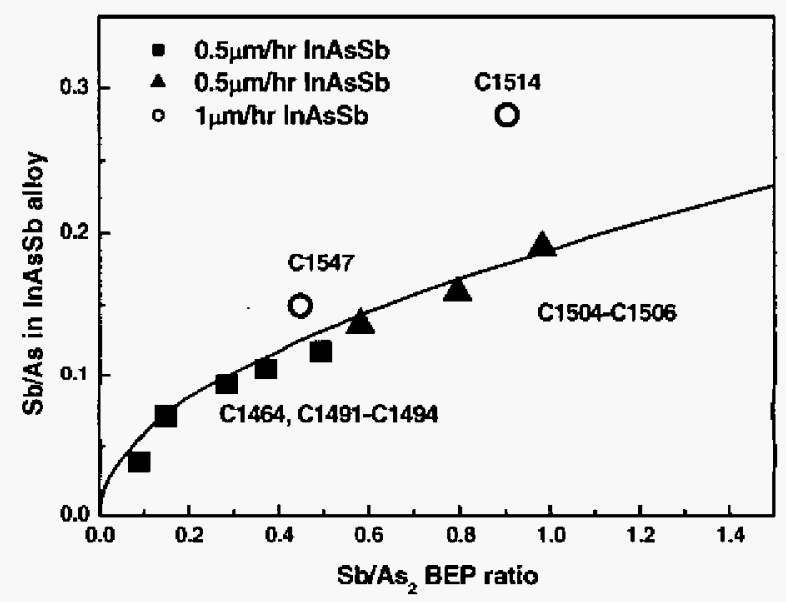

Fig. $2 \mathrm{Sb} / \mathrm{As}$ mole ratio in solid versus the $\mathrm{Sb} / \mathrm{As}_{2}$ beam equivalent pressure ratio (flux ratio) plots for InAsSb/InAs MQW samples. The composition is determined from DXRD measurement.

non-equilibrium thermodynamic model (9) with the published interaction parameters (12) and strain energy (13). It implies that the growth condition for $0.5 \mu \mathrm{m} / \mathrm{hr}$ growth rate might be close to the equilibrium condition and thus the strain-enhanced free energy slows down the $\mathrm{Sb}$ incorporation process. The results of the two samples with $1 \mu \mathrm{m} / \mathrm{hr}$ growth rate are also plotted in Fig. 2. As can be seen in the figure, the high growth rate samples $(\mathrm{C1514}, \mathrm{C1547})$ have better incorporation rate, which implies that the faster growth rate may have driven the growth condition far from the equilibrium condition. The sample with larger lattice mismatch (C1514) shows larger 
(a)

(b)
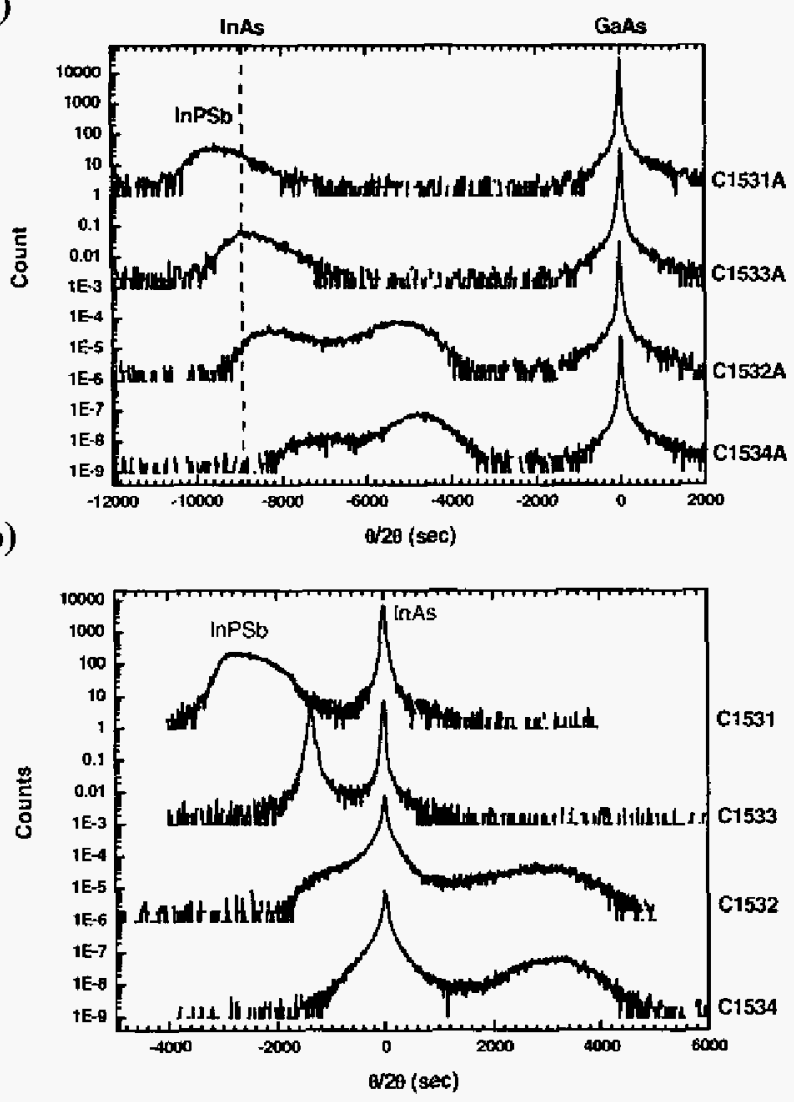

Fig. 3 DXRD spectrums of InPSb layers grown on GaAs (a) and InAs (b) substrates. (Sample number with posifix-"A" implies GaAs substrate sample)

deviation. Though only two experiment data are presented, the trend of the high growth rate samples has better linearity and easier composition control is expected.

With regard to the design of mid-IR heterojunction devices on InAs substrate, we choose $\operatorname{InP}_{0.64} \mathrm{Sb}_{0.31}$ instead of the traditional AlAsSb or InAlAsSb as the cladding layer material since it is aluminum free and lattice matched to InAs substrate (4-6). Fig. 3 (a) and (b) shows the DXRD spectrums of InPSb bulk layers deposited on GaAs and InAs substrates, respectively. As can be scen in Fig. 3, the epilayers of C1532A and C1534A show two broad peaks. It evidences the existence of phase separation in these two samples. The other two samples with higher Sb composition, C1533A and Cl53IA, have only one epilayer peak. However, the peaks are broad and with shoulder in their high angle side. For samples grown on InAs substrate as can be seen in Fig. 3(b), the trend is similar. C1531 has a broad epilayer peak.

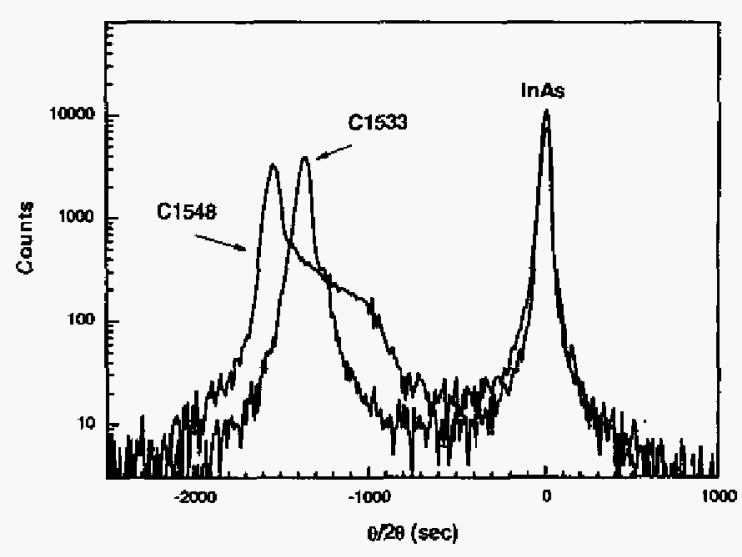

Fig. 4 DXRD spectrums of InPSb layers grown on InAs substrates. The FWHM of C1533 is only 65 arcsec, indicating a good crystal quality. The right shoulder of sample C1548 implies that phase separation may take place in this sampie.

However, as the angle difference is reduced to $\sim 1500$ arcsce, the peak of $\mathrm{Cl} 533$ becomes very sharp. Again, further reducing the $\mathrm{Sb}$ composition splits the epilayer into two phases. In previous study (14), a very large calculated miscibility gap in InPSb alloy extending from $\mathrm{x}=0.02$ to 0.97 at $480^{\circ} \mathrm{C}$ has been reported. However, this result can not be fully applied to the growth of MBE, because the growth condition may deviate from the equilibrium condition. Our finding indicates that the center of the solid miscibility region in our growth condition is around the $\mathrm{Sb}$ composition of 0.3 . To further understand the phase separation in InPSb, the DXRD spectrums of two samples $\mathrm{Cl} 533$ and $\mathrm{C} 1548$ are plotted in Fig. 4. Apparently, sample C1533 exhibits the smallest strain, the angle difference between its InPSb peak and InAs substrate peak is only 1360 arcsec and the FWHM of InPSb signal is only 65 arcsec, which indicates its good crystallinity. Based on the growth condition of $\mathrm{C} 1533$, we adjusted the beam flux of $\mathrm{Sb}$ to reduce the lattice mismatch. As a result, the peak of the spectrum has even larger shift than C1533, and the shoulder at its right side implies slight phase separation in this sample. In addition, the impurity doping during the growth of InPSb were also studied. Preliminary results are listed in Table 1 . It implies that $S i$ and Be can be used as the $n$ and $p$ type impurities in InPSb, respectively. Therefore, InPSb is a promising material for mid-infrared applications. 
Table 1. Hall measurement result of InPSb bulk epilayer with Be and Si dopant.

\begin{tabular}{cccccc}
\hline $\begin{array}{c}\text { Sample } \\
\text { No. }\end{array}$ & Dopant & Type & $\begin{array}{c}\text { Mobility } \\
\left(\mathrm{cm}^{2} / \mathrm{sec}\right)\end{array}$ & $\begin{array}{c}\text { Concentration } \\
\left(\mathrm{cm}^{-3}\right)\end{array}$ & Temp. \\
\hline C1548A & $\mathrm{Be}$ & $\mathrm{P}$ & 16 & $2.6 \times 10^{17}$ & $\mathrm{RT}$ \\
\hline $\mathrm{C} 1549 \mathrm{~A}$ & $\mathrm{Si}$ & $\mathrm{N}$ & 970 & $1.3 \times 10^{18}$ & $\mathrm{RT}$ \\
\hline
\end{tabular}

\section{CONCLUSION}

We investigate the growth condition and optical quality of InAsSb/InAs MQWs structure. The Sb incorporation behavior in the MQWs was addressed and discussed. Strain effect on the incorporation of $\mathrm{Sb}$ was observed. The growth of InPSb was also investigated. Nearly lattice-matehed InPSb layer was successfully grown on InAs substrate. The best layer demonstrates a very narrow DXRD linewidth of 65 arcsec, which indicates the good crystallinity of the sample.

\section{REFERENCES}

(1) P. Werle and A. Popov, "Application of antimonide lasers for gas sensing in the 3-4 $\mu \mathrm{m}$ range", Applied Optics, Vol. 38, No. 9, pp. 1494 (1999).

(2) H. H. Gao, A. Krier and V. V. Sherstnev, "Room-temperature InAs $s_{0,8 y} S_{0.11}$ photodetectors for $\mathrm{CO}$ detection at 4.6 $\mu \mathrm{m}$ ", Applied Phvsics Letters, Vol. 77, No. 6, pp. 872 (2000).

(3) W. Dobbelaere, J. De Boeck, C. Bruynseraede, R. Mertens and G. Borghs, "InAsSb light emitting diodes and their applications in infra-red gas sensors", Electronics Letters, Vol. 29, pp. 890 (1993).

(4) A. Joullie, E. M. Skouri, M. Garcia, P. Grech, A. Wilk, P. Christol, A. N. Baranov, A. Behres, J. Kluth, A. Stein, K. Heime, M. Heuken, S. Rushworth, E. Hulicius and $T$. Simecek, "InAs(PSb)-based "W" quantum well laser diodes emitting near $3.3 \mu \mathrm{m}$ ", Applied Physics Letters, Vol. 76, pp. 2499 (2000)

(5) R. M. Biefeld, J. D. Phillips, and S. R. Kurtz, "Exploring new active regions for type I InAsSb strained-layer lasers", Journal of Electronic Materials, Vol. 29, pp. 91 (2000).
(6) S. R. Kurtz, R. M. Biefeld, A. A. Allerman, A. J. Howard, M. H. Crawford, and M. W. Pelczynski, "Pseudomorphic InAsSb multiple quantum well injection laser emitting at $3.5 \mu \mathrm{m}$ ", Applied Physics Letters, Vol. 68, pp. 1332 (1996).

(7) Y. Rouillard, B. Lambert, Y. Toudic, M. Baudet, M. Gauneau, "On the use of dimeric antimony in molecular beam epitaxy", Journal of Crystal Growth, Vol. 156, 30 (1995).

(8) B. W. Liang, and C. W. Tu, "A kinetic model for As and P incorporation behaviors in GaAsP grown by gas-source molecular beam epitaxy“, Joumal of Applied Physics, Vol. 74, pp. 255 (1995).

(9) A. Yu. Egorov, A. R. Kovsh, V. M. Ustinov, A. E. Zhukov, P. S. Kopev, C. W. Tu, "A thermodynamic analysis of the growth of III-V compounds with two volatile group $\mathrm{V}$ elements by molecular-beam epitaxy", Joumal of Crystal Growth, Vol. 188, pp. 69(1998).

(10) S. D. Wu, L, W. Guo, W. X. Wang, Z. H. Li, X. Z. Shang, H. Y. Hu, Q. Huang, J. M. Zhou, "The incorporation behavior of arsenic and antimony in GaAsSb/GaAs grown by solid source molecular beam epitaxy", Journal of Crystal Growth, Vol. 270, pp. 359 (2004).

(11) A. Wilk, F. Genty, B. Fraisse, G Boissier, P. Grech, M. El Gaouli, P. Christol, J.Oswald, T. Simecek, E. Hlicius and A. Joullie, "MBE growth of InAs/InAsSb/AlAsSb structures for mid-infrared lasers", Joumal of Crystal Crowth, Vol. 223, pp. 341 (2001).

(12) G B. Stringfellow, "Calculation of temary and quaternary III-V phase diagrams", Journal of Crystal Growth, Vol. 27, pp. 21 (1974).

(13) R. E. Nahory, M. A. Pollack, E. D. Beebe, and J. C. DeWinter, "The liquid phase epitaxy of $\mathrm{Al}_{y} \mathrm{Ga}_{1-y} \mathrm{As}_{1-\mathrm{x}} \mathrm{Sb}_{\mathrm{x}}$ and the importance of strain effects near the miscibility gap", Journal of The Electrochemical Society. Vol. 125, pp. 1057 (1978).

(14) M. J. Jou, Y. T. Cherng, and G B. Stringfellow, "Organometallic vapor-phase epitaxyial growth and characterization of the metastable alloy $\mathrm{InP}_{1-1} \mathrm{Sb}_{3}$ ", Joumal of Applied Physics, Vol. 64, pp. 1472 (1988). 